\title{
The Imperceptibility of Style in Danto's Theory of Art: Metaphor and the Artist's Knowledge
}

\author{
Stephen Snyder \\ (Boğaziçi University, Istanbul)
}

\begin{abstract}
:
Arthur Danto's analytic theory of art relies on a form of artistic interpretation that requires access to the art theoretical concepts of the artworld, 'an atmosphere of artistic theory, a knowledge of the history of art: an artworld'. Art, in what Danto refers to as post-history, has become theoretical, yet it is here contended that his explanation of the artist's creative style lacks a theoretical dimension. This article examines Danto's account of style in light of the role the artistic metaphor plays in the interpretation of the artwork, arguing that it is unable to account for the metaphorical power he claims is embedded within the work of art. An artist's style issues from a unique perspective, the way an artist inhabits a specific spot in history. Though each person has such a perspective, when applied aesthetically, it is the key to the articulation of a unique historical meaning in the work of art. At the same time, artists' knowledge of their contribution remains cut off from this perspective, for they are unaware of their self-manifestation of the historical concept of style. This article makes the case that Danto's notion of style, based on Sartre's notion of being-for-itself, cannot fulfil the role he allots it in his theory because, at some level, artists must apprehend their style to create a work of art capable of functioning critically as a countertext. It is only through the apprehension of their style, and dialogical activity that takes place between the artist and the beholders, that the unseen body of artworld theory is formed. Without this, when oriented to the aesthetic, style provides no concept or theory for the mind to behold. This article presents an alternative approach to style that recognizes the role of theory in the creation of metaphor, which would circumvent this problem.
\end{abstract}

Keywords: Danto, Aristotle, Sartre, Habermas, metaphor, style, aesthetics, theory in style, being-for-itself, being-for-others.

CounterText 1.3 (2015): 366-381

DOI: $10.3366 /$ count. 2015.0028

(C) Edinburgh University Press

www.euppublishing.com/journal/count 
In Transfiguration of the Commonplace, the late Arthur Danto (1924-2013) wrote that ' $\mathrm{t}$ ] o understand the artwork is to grasp the metaphor that is, I think, always there' (Danto 1981: 172). For Danto, 'the greatest metaphors of art' are 'those in which the spectator identifies himself with the attributes of the represented character: and sees his or her life in terms of the life depicted'. When the artwork is experienced as such, 'the artwork becomes a metaphor for life and life is transfigured' (172). This revelation follows from a reinterpretation of one's sense data when an object is perceived as an object of art. The commonplace is 'transfigured' when the framework of artistic intention is applied to everyday sensual phenomenon, apprehending it as if it were art, instead of the quotidian. The artist's intention that something be art, embedded within the artwork, opens up a new interpretive dimension, one that challenges or reconfigures the underlying phenomenon on which it is based. The moment that drives this revelatory process is, for Danto, the metaphor. The artwork itself is the catalyst for the transformative process that the metaphor makes possible, but the locus is somehow elsewhere, for it involves the creative intentions of the artist, the interpretation of the beholder, and the meaning of the times, which enters the work through the artist's style. In what Danto calls the era of 'post-historical' art, all styles are equal, and art can take any form. What differentiates the artwork from the everyday in posthistory, what provides the cues showing that an object embodies an interpretable metaphor - differentiating it from an everyday object - is found in the body of artistic theory and concepts he calls the 'artworld' (Danto 1964). In the era of post-history, the artworld becomes a countertext of sorts. It is through the artistic metaphor that the engagement occurs. But the structure of the artworld, external to the individual work, is the theoretical means through which the artwork is interpreted when art, in the era after art, is no longer representational. Danto understands the artworld, in a somewhat Hegelian manner, to be a set of concepts that emerges according to the inner logic of aesthetic history. While agreeing with Danto's account of art as the embodiment of artistic intention, and his claim that the creative metaphor is the key to artistic transfiguration, I find his account of the artworld one-dimensional. If the artworld is not formed through a dialogue among artists and beholders, I fail to see how his account of metaphor can fulfil its task. The key to the metaphor's power to transfigure comes from having great style. However, the account of style that Danto gives, in which the artist is blind to her style, is at the root of the artworld's onedimensionality.

Danto's analytic theory of art relies on a form of artistic interpretation that requires access to the art theoretical concepts of the artworld. In post-history, 'to see something as art requires something the eye cannot decry - an atmosphere of artistic theory, a knowledge of the history of art: an artworld' (Danto 1964: 580). The observation that the pluralistic world of contemporary art is inextricably bound to theory stems from a revelation Danto had on seeing Warhol's Brillo Boxes. Art, in Danto's eyes, had become theoretical, yet his explanation of the artist's creative style lacks a theoretical dimension. The artist's intention, drawn from the narrative meaning of history, endows 
the artwork with meaning. The narrative meaning of history is something akin to the Zeitgeist, or spirit of the times. In a narrative construction, it carries within it the way that the people of a certain historical place and time perceive the world. The artists' style is their unique perspective, the way they inhabit a specific spot in the space-time continuum. Each person has such a perspective (Danto 2007a), ${ }^{1}$ but when applied aesthetically, it is the key to the articulation of a unique historical meaning in the work of art. At the same time, artists' knowledge of their contribution remains cut off from this perspective, for they are unaware of their self-manifestation of the historical concept of style. Here, I examine Danto's account of style in light of the role the artistic metaphor plays in the interpretation of the artwork, arguing that it is unable to account for the metaphorical power he claims is embedded within the work of art. I make the case that his notion of style cannot fulfil the role he allots it in his theory, and suggest an alternative approach that recognises the role of theory in the creation of metaphor. Below, I discuss the role of metaphor in the artwork, and Danto's account of style, making the case that artists must, at some level, apprehend their style to create a work of art capable of functioning critically as a countertext. It is only through the apprehension of their style, and dialogical activity that takes place between the artist and the beholders, that the unseen body of artworld theory is formed. Without this, when oriented to the aesthetic, style provides no concept or theory for the mind to behold.

The problem I address in Danto's theory can be summarised as follows: Danto employs a notion of style that requires, at some level, theoretical activity on the part of the artist. Danto defines the artwork such that it necessitates the activity of the viewer. 'To seek a neutral description is to see the work as a thing and hence not as an artwork: it is analytical to the concept of an artwork that there has to be an interpretation' (Danto 1981: 124). While this claim makes clear that art's existence is underwritten by a hermeneutic practice, Danto deliberately draws a stark line between the task of philosophy and the task of art-art's essential definition and its historical practice. The offshoot of this is that Danto views art criticism and interpretation as a nonphilosophical activity, even if philosophically mandated. As noted above, Danto argues that the active component of art is akin to metaphor. This moment, which lends art the power to be something more than its medium of articulation, has an effect on par with that of rhetoric. Danto lays out a two-phased process of artistic creation. Through their style, artists are able to grasp the meaning manifest in history and embody it in their art. The style of the person has an analogue in the style of history:

[I]n art particularly, it is this external physiognomy of an inner system of representation that I wish to claim style refers to. Of course we speak as well of the style of a period or a culture, but this will refer us ultimately to shared representational modes which define what it is to belong to a period. (Danto 1981: 205)

The artists' style manifests a representation of a world both individual and cultural. Their style, impervious to them is, nonetheless, visible to others, and through the 
beholder's interpretation of the externalisation of that inner-world, artworks are actualised, so to speak.

The artist's style, used to craft the metaphor that makes the work of art successful, for Danto, works in a manner similar to rhetoric. However, Danto's definition of style, as I aim to show, fails to provide the artwork with the power of rhetoric, for, if nothing else, rhetoric is a carefully aimed tool. If there is a lack of awareness in the process of artistic creation and interpretation, it is with the audience intuitively filling in what is missing. The activity of rhetoricians, who know well the ellipsis the audience should complete, is not blind to the context of their world. As I argue below, Danto's narrative theory of art entails a rich notion of metaphor. Nonetheless, the role metaphor plays in the realisation of artistic engagement is only sustainable if his account of style acknowledges the interaction between creator and beholder that must exist when the artwork's intention comes into being. Nonetheless, this theoretical attitude, implicit in the style of artists, is not limited to knowledge of their craft and their audience. It is also present in the transmission of the artistic intention, an interactive process initiated with the audience. Unlike rhetoric, which aims to manipulate, this process furthers the beholder's understanding of the cultural schemata the artist uses to communicate, and in this sense it is philosophical.

Essentialist definition of art. Despite his grounding in the tradition of analytic philosophy, Danto's theory of art draws heavily on the aesthetics of Hegel. ${ }^{2}$ It was Hegel's assertion that the artwork was the material incarnation of spirit's historical striving for truth. Incorporating this aspect of Hegel's aesthetic theory directly into his essentialist definition of art, Danto argues that all art of all times could be construed as embodied meaning. He understands the artwork to have two necessary attributes. First, it must have material form, and second, the material form must incorporate the meaningful intention of the artist. In agreement with Hegel, Danto's aesthetic theory requires that the meanings of the artworks be connected through a historically indexed notion of style. The historical indexing of style ensures that artworks can be interpreted through the progressively emerging concepts of the artworld. Danto views contemporary art as an infinitely pluralistic style of making styles. In the post-historical world of art, no style is better than any other. It is Danto's understanding that, in our time, the story of art has closed, which leads to his claim that the 'era of art' is over. The culture of contemporary art allows that all styles are available to artists, though none can be inhabited as they were by the artists of past eras. Because the style of each period is historically indexed, in Danto's view, artworks entail temporally unique metaphors. Though the meanings of the artistic metaphors shift across time, they are, nonetheless, interpretable because they are understood through the legacy of artworld theories.

Though Danto draws on a Hegelian model, he is critical of Hegel's teleological notion of substantial, or universal, history. Danto bases his theory on the analytic model of historical narrative, which he pioneered in Analytical Philosophy of History. To explain his theory, Danto uses the example of the Thirty Years' War. In 1618 it could 
not have been stated that 'the Thirty Years' War has begun'. Only from the perspective of future historians, after the war's completion, could one make reference to the Thirty Years' War. According to Danto, when narrative historical models are employed, the narrative structure is only useful when looking backward (2007a: 152). Thus, any attempt to project a historical theory into the future is little more than 'prophecy'. Danto views the projects of all substantial philosophers of history as flawed, for they make claims about the future that utilise knowledge of a universal history they cannot possibly have. The universal perspective relies on a theory that conceives of history as a rationally discernible whole. The philosopher, as they see it, has privileged access to the theoretical totality, and based on the rational consistency of the historical whole, can 'peek' into the future. Danto agrees that history is formed based on theories, or the 'interests' of the historian (2007a: 142). As mentioned above, these are only valid when looking back at a set of events to which a narrative explanation is applied. As a consequence, utilising one's current narrative structure to anticipate a possible future is invalid. This aspect of Danto's essentialist / narrative account of art has ramifications insofar as he postulates that the artist is blind to what is at the root of aesthetic meaning. In terms of the artwork's embodiment of meaning, Danto's theory of artistic creation mirrors that of Hegel, who viewed artists as vehicles of spirit, creating works that embody a form of truth beyond their immediate understanding. But if Danto disallows a substantial account of history, which has universal meaning embedded within it, the theoretical perspective that endows the work with meaning cannot be blindly bestowed on the work of art. Without the Hegelian spirit-of-the-times, the artist must create the meaning, and the unselfconscious nature of the relationship that artists have to their artworks does not adequately clarify the theoretical perspective that is bound to the style of post-history. On one level, I agree that artists might not be aware of the manner of their time. However, though it was not Danto's intention, his understanding of artistic creation, rooted in the artist's style, places limits on the possibility of theoretical reflection occurring in the interchange between artist and audience. This interchange should be an iterative loop, with the artist reflecting upon the feedback of the audience, thereby incorporating new stylistic features into new work. The alternative model represents an option for art to play an active and critical role in the reproduction of culture. However, if artists are unaware of their style, drawing unreflectively on their inner system of representation, then the critical feedback mechanism is truncated, lessening the potential to advance a critical hermeneutic dialogue.

Style. Plato is critical of the rhapsode Ion, whose Homeric renderings far surpass the efforts of others. Despite this ability when reciting other poets, Ion's performance is lacking. Thus, Socrates claims that the 'song stitcher' is 'unable to speak on Homer

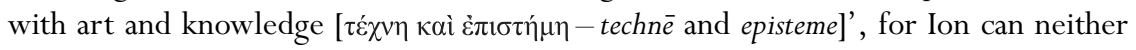
explain nor reproduce the quality of his Homeric recitations (Plato 1960: 532c). It is Plato's aim to convince us that art is either a distorted copy of the real or irrational incantations. Without accepting the conclusions of Plato's critique of art, 
Danto acknowledges the claim that Ion recites without 'knowledge or art' (1981: 198-201). Socrates concludes that Ion's inexplicable ability issues not from craft but from divine power.

For the poet is a light and winged and sacred thing, and is unable to indite until he has been inspired and put out of his senses, and his mind is no longer in him .... For not by art do they utter these things, but by divine influence; since, if they had fully learnt by art to speak on one kind of theme, they would know how to speak on all. (Plato 1960: 534b)

Danto agrees that this ability is not a craft, for it cannot be learned. It is a gift, the gift of style.

Style, for Danto, encompasses the ability to apprehend directly what others intuit indirectly. Those who do not possess style must imitate. Imitators can acquire a manner by learning, but only by imitating those with style. Thus, when one has learned the manner of style, one 'knows' in a mediated fashion, whereas the one who manifests style prehends it in an unmediated way. Artists like Ion, who demonstrate an innate sense of style, are unable to explain their talent, for they are in possession of something akin to divine dispensation.

Danto defines style as the physiognomic self-representation of the artist. This representation, imperceptible to artists, is nonetheless perceptible to the audience. Style, for artists, is a manifestation of the way they view and inhabit the world, something of which they are not conscious. This notion of unconscious style seems to be drawn from Sartre, from whom Danto acknowledges he has learned much (Danto 1975: 12). Danto is looking at Sartre's unique understanding of being-for-itself and for-others, être-pour-soi and être-pour-autrui, when he defines the impenetrable nature of one's own style (Danto 1981: 10-11). Referring to Sartre's discussion of language's inability to apprehend actual existence, he writes:

In the light of what had heretofore been deemed a necessary condition for language to represent the world, it would entail the view that since this condition fails, language cannot represent the world at all, and that the world as it really is lies beyond the power of language to say. (1975: 18)

The world itself, something like the inner system of representation that Danto refers to as style, in Sartre's account is linguistically off limits. Individuals cannot speak of, or represent, 'world' to others, for they are themselves unaware of it. For Danto, we perceive the inner-world of others, externally manifest, but only as the flipside of the imperceptible self that is forever beyond our reach. Thus, for Sartre, one can only become aware of one's particular location in existence through the gaze of the other. Through the look of the other, one becomes aware of oneself. 'But in perceiving an eye as looking, I perceive myself as a possible object for that look: I lose my transparency, as it were, and become opaque even for myself' (Danto 1975: 117).

This, for Sartre, was hell. 'The structure of self-consciousness, then, is logically social, but since I finally am an object for myself only through the provenance of 
others' perception of me, what I am (as an object) depends upon others and not upon myself' (Danto 1975: 120). The opacity, the murky awareness one has when the imperceptibility of one's locus in the world fades, is critical to understanding that the other has a position. To know the self, pour-autrui, is the start of self-reflection and critique. But style remains at the level of pour-soi.

This notion of style links the artist's work to its historical context (Danto 1981: 205). Understood thus, the internal perspective cannot be grasped. But the external version of the inner-self is what makes the artwork interpretable to audiences of that time, as well as those of the future. This way of colouring the world, embodied within the work's medium of presentation, entices the audience to interpret it. Thus, the essence of the work of art comes through its interpretation, 'esse is interpretari', because the artwork is created such that it must be interpreted (Danto 1981: 125). If the artwork does not evoke an interpretation, even one of negative evaluation, then it fails as an artwork. Hence, through the higher powers of intuition extant in their style, and without direct knowledge of how they do it, artists must create an interpretable metaphor. I question though, whether a great metaphor can be created so blindly, as a 'shot in the dark'?

Metaphor and enthymeme. I began with Danto's claim that ' $\mathrm{t}] \mathrm{o}$ understand the artwork is to grasp the metaphor that is, I think, always there' (1981: 172). The beholders, when encountering the artwork, open the metaphor within the work, interpreting it within the framework of their own lives. When one can identify oneself with something placed in the metaphor, perhaps intuiting that the externalised representation of self, articulated through artistic style, is something that matches some aspect of one's own inner-world, it becomes, if not a universal, something that we all can step into, even if for a moment. When this is achieved 'the artwork becomes a metaphor for life and life is transfigured' (172). Experiencing such a work is 'the enactment of a metaphoric transformation' through which the commonplace is transfigured into something 'amazing' (173).

The role of metaphor in mediating the components of style and rhetoric can be described as follows: first, the artists' style, the physiognomy of the self, creates the metaphor, for 'metaphors have to be made' (Danto 1981: 175). Nonetheless, this process is not a conscious one, for the artists' style, the consciousness of the world they embody in their works, is hidden from them. Second, the metaphor manifests rhetorical characteristics, for its purpose is to provoke the audience, to effect some feeling in them that completes the artists' gestures of meaning. The relationship between the artists and the audience is such that the artists' intentions, in a rhetorical fashion, evoke a response from the viewer, completing the metaphorical ellipsis. The locus of this aesthetic engagement is outside of the work itself, for the work merely induces a response. For the rhetorician, the intended response is known to the creator. The artistic expression, on the other hand, leaves open an unbounded space for interpretation. 
Danto references Aristotle's discussion of the enthymeme in Rhetoric, suggesting that the artistic metaphor is similar to the enthymeme, a syllogism with a missing step. ${ }^{3}$ Though Aristotle discusses many different forms of the syllogistic enthymeme, the type that contains a maxim as an unstated part of the syllogism is the form pertinent to Danto's discussion (Aristotle 1926: II, 21, 1394a). This implies that the one using the enthymeme, and Aristotle is clear that its usage is to manipulate the audience, must have some knowledge of the addressees and their wishes in order to imply an acceptable maxim in the place of the missing part. The maxim is a general statement that will go unquestioned by the audience. It is refutable, but it will not be questioned immediately if the metaphor it employs is neither too far-fetched nor too obvious (Aristotle 1926: III, 10, 1410b). 'Now, a maxim is a statement, not however concerning particulars, as, for instance, what sort of a man Iphicrates was, but general; it does not even deal with all general things ... but with objects of human action' (Aristotle 1926: II, 21, 1394a). The orator must know the audience. The metaphor couched within the maxim must go unnoticed, compelling the audience to complete the persuasive syllogism without scrutiny. The maxim will be something like a 'class-type', or part of the narrative of a people that they take for granted. In Narration and Knowledge, Danto gives the example of the kind person. A kind person will be predictably kind, but exactly how they will be kind is not predictable. Without the rules behind the class-type being specifically mentioned, people living in a given place and time will be unaware of this aspect of their local narrative or inner-world. The rhetorician, however, must know these customs. Because this information is common to a people, they will assume there are no 'general laws' to be known (Danto 2007a: 223-27). But this is the mistake the rhetorician takes advantage of, using these 'rules' or maxims as the missing step of the enthymeme. The missing step is completed in the hearer's mind. The artist's style, in some way, will place these 'pieces' together, adding a step of which neither artist nor beholder are explicitly aware, but which is nonetheless filled in through the activity of the beholder. For this reason, I refer to this process as opaque, for though hidden in some ways, there is still an implicit inner logic.

It is Danto's claim that the metaphoric meaning, hidden as it were within the enthymeme, shares the structure of the metaphor embodied within the artwork. The rhetorical component in the work of art, though not the exact equivalent of its linguistic counterpart, functions in much the same way. It is the rhetorical element of metaphor that transfigures one mode of speech into another. The words retain the same meaning, but in their usage they acquire new meanings; they are 'transfigured' and not 'transformed' (Danto 1981: 168). In the form of an enthymeme, the transfiguration occurs when the listener is made to fill in the gap. The listener is compelled to make the connection, guided by the rhetorician to fill in the ellipsis. The critical piece, in Danto's account, is that Aristotle has 'identified something crucial: the middle term has to be found, the gap has to be filled in, the mind moved to action' (Danto 1981: 171). The metaphor, in Danto's schema, is a minor work of art. 
It is about words in the same way that an artwork is about things in the real world. This metaphoric representation exhibits the artwork's embedded intention. For Danto, perceiving the contrast in forms of usage is essential because 'to understand the artwork is to grasp the metaphor' within (172). Like the aesthetic metaphor conjured by the artist for the work of art, the maxim that makes the enthymeme effective is a gesture or a generalisation specific to a cultural context. Hence, a considerable level of 'cultural competence' is needed to implant the metaphoric gesture in the syllogism (Danto 1981: 177). Like the maxim, which functions within a shifting historical and cultural context, artistic metaphors can become stale, change, or be forgotten. It is often necessary, Danto contends, that the metaphors of art require 'scholarly resurrection'. Thus, 'it is the great value of such disciplines as the history of art and of literature to make such works approachable again (Danto 1981: 174). The world of metaphor requires a heightened level of cultural competence to access and manipulate; therefore, if one has no such cultural competence, one will not understand, much less create, a metaphor. This culturally elevated metaphoric layer is the theoretical medium of the artworld. In the process of transfiguration, it is Danto's claim that an object is detached from reality and placed in another world, a sphere of interpreted things, manifest with the gesture of metaphor. 'So it is essential to our study that we understand the nature of an art theory, which is so powerful a thing as to detach objects from the real world and make them part of a different world, an art world, a world of interpreted things' (Danto 1981: 135). The process of metaphoric creation, embodiment, and interpretation 'involves a complex interrelation between the framer and the reader of the enthymeme (Danto 1981: 170). This indicates that the real medium of the work of art, what separates it from objects of the everyday, lies in the interactive medium of human consciousness. The interaction that occurs within consciousness plays the levels of inner- and external-representations of world, pour-soi and pour-autrui, off of each other, as text and countertext. Danto argues steadfastly that the inner-representation of one's world is off limits to consciousness or critique. But he makes it clear that when something in one's inner-representation of world does not match one's world, it becomes opaque (2007a: 223). One no longer glides seamlessly in one's world. Regarding general laws and customs of a specific culture, if one is of that culture, one may never need an explanation for a given event. But if one does not have the cultural competency needed, as an outsider for example, the world may not be clear - events may need explanation, a rule may become explicit and opaque. It is this loss of imperceptibility in the rules of art, and the increasing need for the concepts behind them to be explained, which demands the theoretical intervention of the artworld (Snyder 2015). But this account of the artworld, the theoretical account of art's burgeoning class-type which accepts all objects as art, does not comport with the unreflective articulation of style. The opacity evokes an interaction, an interaction that goes beyond the bounds of the conventional audience and what had been considered the standard forms of art. Danto was correct in noting this aspect of the post-historical dynamic of the artworld. But this account of metaphor 
stands in contrast to Danto's notion of style and the inner-world that underwrites it. It does not accord with his notion of an artworld as a set of unfolding artistic concepts. Rather, his notion of artistic metaphor demands a dialogue of concepts, provoked by artistic creation, which is cogent enough to result in the body of theoretical, and sometimes counter-theoretical, knowledge that sets, or refuses to set, the parameters for art's future, while also explaining its past.

Style's transitive property. Danto's account of artistic creation and reception includes style as 'the relationship between representation and the one who makes the representation', and rhetoric 'concerns the relation between representation and audience' (Danto 1981: 198). The gift possessed by Ion is the epitome of what Danto refers to as style: the unmediated ability to speak the words of Homer in a way that cannot be learned. Unmediated expression, when embodied in art, provides those who will interpret the work with the opportunity to experience the stylised incarnation of artistic consciousness that the artists themselves cannot intuit. Ironically, Danto accepts the notion of style as the conduit for artistic meaning, which compels Plato to ban the poets from the polis. In his dialogue with Ion, Socrates compares the inspired performances of Ion to the Heraclean loadstone, or a magnet, which, as we know, will attract iron rings (Plato 1960: 533d-536d). Socrates argues that like the magnetic power of the stone, what is imparted upon the words or images of art through divine inspiration can be transferred to others. An iron ring, having no magnetic power of its own, is transformed through contact with the magnet. By touching the magnet, it receives the magnetic force, and a chain is created, with one ring transferring the force to the next. Socrates tells Ion that the poet, and the rhapsode in this dialogue, has divine inspiration. The rhapsode, reciting the poet's work, is possessed by the poet's enchantment in the same manner that the magnet bestows the iron ring with its power. The rhapsodists, like the iron rings, are able to transmit this divine dispensation to others. The last ring on the chain is the spectator, where the transfer of the poet's energy stops. Danto's example of the fugue machine reflects how closely his account of artistic style resembles Plato's. It was claimed that Bach had invented a 'fugue-writing machine', which could produce fugues according to a formula. Danto speculates that if such a machine existed, its products would possess no style (1981: 203). Without the unmediated presence of style, a craft would result that possessed no transfiguring power. There would be nothing present in the work to interpret.

Danto proposes that the metaphor is the medium through which art transmits its rhetorical 'intention'. But Danto's theory of how artists create metaphors out of the gift of style does not account for the critical role metaphor plays in the artwork's ability to effect a reaction in the audience. The employment and creation of the metaphor is tied to the 'cultural competency' and the ability of artists to read the subtext of historical meaning. The transmission of the intention through the elliptical enthymeme is a notion found in the work of Aristotle, who sought to refute Plato's theory of art by showing that art was not created through inspiration - its power not transmitted as the loadstone's power - but was a technē capable of evoking a practical effect on 
the audience. The comparison of the artwork to the enthymeme is compelling. It provides an avenue through which one can understand the link between the effect art has on the audience and the cultural realm from which the artist draws. But this claim requires more than the artist's unselfconscious revelation of meaning to sustain the connection. It also requires the artist to craft the enthymeme such that the metaphor evokes a response from the audience, bringing to light the artwork's meaning.

Discussing how the great poets elevate language above its standard usage, bringing greater clarity to the topic, Aristotle maintains that 'their greatest asset is a capacity for metaphor'. In line with Danto's claim, Aristotle continues, 'this alone cannot be acquired from another, and is a sign of natural gifts' (Aristotle 1999: 1459a, 5-8). But the power of the poet to create metaphor comes from the capacity 'to discern similarities'. In Rhetoric, reiterating assertions he made in Poetics, Aristotle states that the power of the poem, as that of prose, comes from the metaphor, which 'cannot be learnt from anyone else' (Aristotle 1926: 1405a, 9). Nonetheless, even if one has the gift of creating metaphor, if it is to be effective the gift must be employed appropriately. 'This will be secured by observing due proportion; otherwise there will be a lack of propriety, because it is when placed in juxtaposition that contraries are most evident' (Aristotle 1926: 1405a, 9-10). Regardless of whether we accept in total Aristotle's rules of deployment, we can agree that the successful usage is achieved through the apt and conscious application of the metaphor, which involves knowledge of the audience and its placement in the context that best affords the desired effect. It is clear that practical usage of rhetoric found in metaphor, the same power the artwork utilises to affect the audience, is a techne requiring an interrelationship between the artist and the audience. Because the conveyance of style that Danto describes is one-way, this aspect of metaphoric usage is not included in Danto's account of style and rhetoric. The pour-soi notion of style that Danto adapts from Sartre's notion of unreflectiveconsciousness (être-pour-soi) relies on a struggle, the overcoming of the other, for realisation. Even Sartre seemed to understand this state of being was impossible, for the one-way model he envisioned was fundamentally unsatisfying (hell is other people). The self is transformed through the recognition that one exists in the gaze of the other (Danto 1975: 121-25). For Danto, the intention of the artist evokes the interpretation of the other, and in stepping into the metaphor they are transfigured, not overcome. The metaphor is fundamentally interactive, and through the artwork, the audience is invited to interpret what the artist receives from history. But the model of unselfconscious style leaves little room for transformation or change in the transmission of culture through art.

Art does something. The end of art's disenfranchisement, as Danto sees it, comes with the art of post-history when the task of art is separated from the task of philosophy. As the era of art closes, philosophy can play a role in art's definition because its historical narrative is complete. This implies, however, that art made after the end of art's history is free of philosophical interference. Artists plumb the meaning of history and evince it in their art. Philosophy will have no role in artistic creation, but 
the philosopher-critic is needed to interpret the meaning embodied in the work. In the era of post-history, for Danto, art is free, but philosophy's disenfranchisement of art had a long history. Philosophy's marginalisation of art reduces art's status by arguing that either it does nothing or that it is irrational. To overcome this, Danto asserts it must be recognised that art does something. In this, Danto acknowledges Plato's fear of art's power without succumbing to his desire to banish art from the realm of intelligible reality (Danto 1986). However, Danto's account of the generation of metaphor through the unconscious medium of style minimises art's potential for effecting change through its meaning. The lack of control artists have over their gift, as Danto describes it, would actually support Plato's fear of the artists' irrational power rather than allay them. In Danto's theory of style, the artist's embodiment of meaning underwrites an uncritical ontological existence, which relies on an unmediated connection to stylistic revelation to maintain its essential distance from the history in which the artwork is embedded. Certainly, artists possess a gift, for without their superior intuitions, their works would not raise art - visual, poetic or any another medium - to the elevated status achieved through the artists' transfiguration. But without contesting artists' superior intuitions, removing the stipulation of style's impenetrable metaphoric generation would make room for a formulation of artistic creation that better supports a notion of art capable of evoking critical self-reflection. Each new interpretation of the art object, according to Danto, yields a new artwork $(\mathrm{I}(\mathrm{o})=\mathrm{W})(1981$ : 125). This account of art's essential and interpretable nature flows out of Danto's notion of embodied meaning. This notion of embodied meaning is fundamentally Hegelian, as is the notion of style that is transmitted unconsciously through the artist. But with a theory of art that is underwritten by a narrative framework, rather than a Hegelian absolute, Danto's claim that the artwork is essentially an interpreted medium belies the narrow ontological definition of the artwork's stylistic provenance. ${ }^{4}$ The infusion of an unmediated style into the artwork truncates the interpretive activity, the critical subjectivity, of the audience. The Sartrean model of style that Danto adopts (beingfor-the-self and being-for-others) does reflect the recognition of the other. This is seen in Danto's claim that the artwork must be interpreted to exist as art. But this notion of style and interpretation is based on a model that understands dominance to be the aim of one form of consciousness (pour-soi) over another (pour-autrui). Translated into Danto's notion of style, intention, and audience interpretation, this could account for an aesthetic transformation, but it would be 'blind luck'. 'Arbitrary', as Danto referred to it in terms of future predictions. The process through which art comes into being, as an interaction among artists, artwork, and beholders, must at some level be aimed if it is to manifest a concept that can take its place in the artworld. Without the artist's creative reason, the narrative framework cannot carry the Hegelian spirit that endows history with meaning. Aristotle held the poem to be more philosophical than historical writing because within it was a universal not found in the ordinary sequence of events. Though each historical period is unique, it is the artist, not history, manifesting art with meaning. It is my contention that mind is imparted to 
the aesthetic medium through style. Thus, style evokes an activity that engages the concepts of the artworld through the interpretive act. If the style merely transmits some effect that dissipates in aesthetic reception, then the audience's interpretation, like the iron rings without the magnet, could produce no new artwork. The magnetic force does in some way transfigure, and it dominates what it touches with the force of its style. The nature of the interplay between artist and beholder may, in some ways, as Sartre imagined the relation among egos, be agonistic. But the conflict, the difference in inner representations we perceive through art, is capable of driving thought and interpretation further. The revelation that comes through the play of text and countertext, through the interaction of style, artwork, and audience, opens the way for future understanding of oneself and others. This openness cannot be defined merely by the one-way dispensation of style.

Style and theory. Danto agrees that Plato's depiction of Ion was unfair. Ion does have knowledge of his audience, of what would sway them one way or another, but it was a knowledge Ion could not pass on to others. It could have been that Ion's heightened performance of Homeric verse was not due to his ability, but to the power of Homer's works. After all, the transferral of poetic power does rely on the potency of the initial poem, and Homer's works held so much more than the other poets of Ion's day (Danto 2007b: 16-18). Arguably, the great artist is in possession of a knowledge that is not easily transferred. This supports in some measure Danto's belief that the artist is unaware of his style. But this is not the aspect of Danto's notion of style I challenge, nor do I question Danto's claim that the style of the artist provides a unique stamp of the manner and meaning of the time, providing a way to differentiate the theoretical embodiment of works of one era from another. What is questioned here is the level and type of interaction that occurs with the audience and what it is that artists transmit through their style. Agreeing with Danto that the artist's style manifests the imprint of the times, an account of style is needed that goes beyond the artist's un-selfreflective physiognomic projection. Not only is Danto's unmediated notion of style insufficient to account for the powerful notion of metaphor he argues is central to the work of art, it seems inadequate to carry forward the concepts of the artworld that unfold from the artist's activity.

It would seem that Danto needs an account of style that allows him to maintain the line he draws between the philosophical universal and the particular activity of history. The narrative framework Danto employs provides a 'cognitive reference system' for the members of a given society at a given time (Habermas 1987: 136). This frame of reference provides the 'totality' of ways that the world can be talked about and what stories can be told. When an artwork is created, in Danto's eyes, it forms a metaphor that others can step into (1986: 154). This metaphor goes beyond the allusion to specific events that occur within the narrative frame of reference, requiring for its creation a theoretical perspective that refers to the narrative system as a whole. But, recalling Danto's claims from his Analytical Philosophy of History, he holds that the theoretical perspective used to project a narrative structure beyond a 
particular sequence of events is invalid. All such attempts are arbitrary expressions, and accordingly their value in guiding one's life amount to little more than prophecy. I argue that Danto has made an error here. ${ }^{5}$ Through the theoretical perspective, works of art gain the capacity to present aspects of the lived world that the audience apprehends without explicitly using. If a theoretical perspective were not employed, the metaphor could not embody a gesture of general human interest and could not succeed in manifesting the style of the time, leaving nothing for audiences to interpret.

Aristotle argued that artists do have knowledge of what they create; thus, artistic creation is a techne. This is not to say that the power of art is clearly palpable, that the creative process is a purely rational one. After all, public scrutiny would dissolve art's mystery - the rationalistic Socratic notion of what good art ought to be could well have led to what Nietzsche argued was the death of tragedy. Though the message of art and the process of its creation is opaque, not subject to strict demonstration, it is not unseeingly conjured; the craft of artists entails knowing how to wield their 'divine dispensation'. Aristotle held that humans enjoy the interpretation of art, using reason to understand and recognise what the artist had created (Aristotle 1999: 1448b, 14-19). If we accept that artists have knowledge of their craft, it follows that when they communicate to the audience, it engages them in a way that at some level is theoretical. Danto's response to a commentator who asserted that he had reduced Warhol's style to his aura was that Warhol's style was in his ideas. Referring to Warhol's Brillo Boxes, Danto felt that there were 'no special Warhol touches on any of the cartons. The touch, if anywhere, was in the idea, and so invisible' (Danto 2007b: 22). Artists - whether poets, painters or musicians - are not philosophers. They may utilise the theoretical attitude unconsciously through their style. But through their style, artists use their knowledge of the narrative framework, and their audiences' understanding of it. This allows the presentation of the narrative reference system - which members of a society inhabit from within - outside the context of its everyday employment. In this way, audiences discern the indiscernible. When the narrative structure of the lived world is revealed in this way, something important is disclosed to beholders, allowing them the opportunity to reflect critically on their cultural pre-understandings. This act of reflection is implicitly theoretical. Echoing Kant, the aesthetic idea is encountered when the faculties of mind are employed for purposes other than cognition. Artists manifest aesthetically the narrative reference system that is always in use such that a general understanding of the normally imperceptible framework emerges through their style. Hence, the theory in style is implicit in every artistic metaphor. The process of metaphoric creation entails a dialogue that relies on the interaction of artists and audience. Though artists may not explicitly cognise their intent, they make art to achieve some effect, and this process cannot be completely outside of consciousness. The opaque communication offered by the artist may work in the same manner as rhetoric. And though the power of rhetoric should be feared, as Plato claimed, its uses go beyond that of deception. The rhetorical power of art is able to provide an opaque metaphor, using its elliptical properties to intimate concepts that prosaic expression 


\section{CounterText}

cannot achieve. I argue though, that achieving such an effect through the opacity of the artistic medium is not possible without the conscious efforts of artists to understand and interact with their audience and their history. Sartre held that freedom is less a capacity to choose than choosing to choose. Commenting on this, Danto applies this to style, speculating that the choice one makes constitutes one's style. It is the choice of the kind of life one wills that pervades all other choices, and this can be perceived as style. 'It is that in each choice I do more than choose a specific course of action; rather, I choose a style of choosing. So the original choice is made in every choice' (Danto 1975: 137). Though I agree that the choice will pervade other aspects of one's actions, the choice is not impenetrable. I would say, to the contrary, that it is through their understanding of the concepts and meaning of their time, and their ability to revise these, that artists project a theoretical action in their style.

\section{Notes}

1. See chapter XIII, 'Historical Understanding: The Problem of Other Periods'.

2. In Daniel Dennett's The Philosophical Lexicon, a collection consisting of puns based on philosophers' names, Dennett creates an entry referring to Danto as the 'arthurdantist': 'One who straightens the teeth of exotic dogmas' (Dennett 2008). Danto, often referring to Dennett's lexical innovation, appears to accept this humorous depiction, conceding that he has sought to straighten a few of the 'exotic' philosophies of the historical canon for, in his words, an analytical audience.

3. 'We have already said that the enthymeme $(\dot{\varepsilon} v \theta \dot{v} \mu \eta \mu \alpha)$ is a kind of syllogism, what makes it so, and in what it differs from the dialectic syllogisms; for the conclusion must neither be drawn from too far back nor should it include all the steps of the argument' (Aristotle 1926: II, 22, 1395b).

4. For further elaboration, see Snyder 2010.

5. See Jürgen Habermas' discussion of narrative structure and the 'hermeneutical point of departure' (1977: $346-50)$.

\section{References}

Aristotle (1926), The 'Art' of Rhetoric, trans. John Henry Freese, New York: G. P. Putnam \& Sons.

Aristotle (1999), Poetics, in Aristotle on Poetics, Longinus on the Sublime, Demetrius on Style, trans. Stephen Halliwell, W. H. Fyfe and Doreen C. Innes, Cambridge MA: Harvard University Press.

Danto, Arthur (1964), 'The Artworld', Journal of Philosophy, 61: 571-84.

Danto, Arthur (1975), Sartre, Glasgow: Fontana / Collins.

Danto, Arthur (1981), The Transfiguration of the Commonplace, Cambridge MA: Harvard University Press.

Danto, Arthur (1986), The Philosophical Disenfranchisement of Art, New York: Columbia University Press.

Danto, Arthur (2007a), Narration and Knowledge, New York: Columbia University Press.

Danto, Arthur (2007b), 'The Transfiguration Transfigured: Concluding Remarks', 'Online Conference in Aesthetics: Arthur Danto's Transfiguration of the Commonplace-25 Years Later', < http://artmind. typepad.com/onlineconference $>$ [accessed 10 February 2010].

Dennett, Daniel (2008), The Philosophical Lexicon, www.philosophicallexicon.com [accessed 31 August 2015].

Habermas, Jürgen (1977), 'A Review of Gadamer's Truth and Method', in Fred R. Dallmayr and Thomas A. McCarthy (eds), Understanding and Social Inquiry, Notre Dame: University of Notre Dame Press, pp. 335-63.

Habermas, Jürgen (1987), The Theory of Communicative Action, vol.II: Lifeworld and System: A Critique of Functionalist Reason, trans. Thomas McCarthy, Boston, MA: Beacon Press. 
The Imperceptibility of Style

Plato (1960), Ion in Plato in Twelve Volumes, trans. W. R. M. Lamb, vol. VIII, Cambridge MA: Harvard University Press.

Snyder, Stephen (2010), 'Arthur Danto's Andy Warhol: The Embodiment of Theory in Art and the Pragmatic Turn', Leitmotiv: Topics in Aesthetics and Philosophy of Art 1: 135-51.

Snyder, Stephen (2015), 'Danto's Narrative Philosophy of History and the End of Art: Does Inexplicability Mean Freedom?' in 'Art in the World Today', ed. Ray Kolcaba, special issue, Philosophy in the Contemporary World, 22,1, 50-66. 